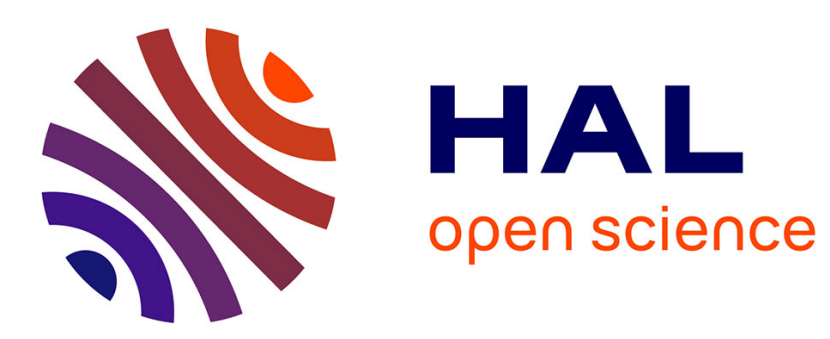

\title{
Building Chinese Request Pattern Graphs for Chinese-Korean Translation
}

Jiabin Li, Changhoe Hwang, Jeesun Nam

\section{To cite this version:}

Jiabin Li, Changhoe Hwang, Jeesun Nam. Building Chinese Request Pattern Graphs for Chinese-Korean Translation. The Journal of Linguistics Science, 2020, 95, pp.201-231. 10.21296/jls.2020.12.95.201 . hal-03242066

\section{HAL Id: hal-03242066 https://hal.science/hal-03242066}

Submitted on 30 May 2021

HAL is a multi-disciplinary open access archive for the deposit and dissemination of scientific research documents, whether they are published or not. The documents may come from teaching and research institutions in France or abroad, or from public or private research centers.
L'archive ouverte pluridisciplinaire HAL, est destinée au dépôt et à la diffusion de documents scientifiques de niveau recherche, publiés ou non, émanant des établissements d'enseignement et de recherche français ou étrangers, des laboratoires publics ou privés. 


\title{
Building Chinese Request Pattern Graphs for Chinese-Korean Translation ${ }^{* 1)}$
}

\author{
Jiabin $\mathrm{Li} \cdot$ Changhoe Hwang $\cdot$ Jeesun Nam**2) \\ (Hankuk University of Foreign Studies / MA Candidate $\cdot$ MA
}

Candidate $\cdot$ Professor)

Li, Jiabin., Changhoe Hwang, and Jeesun Nam. 2020. "Building Chinese Request Pattern Graphs for Chinese-Korean Translation." The Journal of Linguistic Science 95:0-0. This paper aims to describe diverse request patterns in Chinese for the automatic classification and the Chinese-Korean translation of music-request sentences in $\mathrm{AI}$ assistant platforms. These patterns are formalized by Local-Grammar Graphs (LGGs), a finite-state grammar, and represented under directed acyclic graphs based on the main function categories. The UNITEX graph editor has been used to construct Chinese LGGs and the request pattern tags that are proposed for Korean sentences based on DECO Korean Electronic dictionaries was applied. The result of this study has been examined and evaluated by being compared with Google Translate results at the end of the paper. Experimental results prove that the LGG grammar constructed in this paper can effectively cover and annotate various request patterns. This will provide the possibility to generate a large-scale bilingual annotation corpus in the field of music listening. (Hankuk University of Foreign Studies)

1) This work was supported by Hankuk University of Foreign Studies Research Fund of 2020.

2) Jiabin Li (First Author); Jeesun Nam (Corresponding Author). 
Key Words Chinese Request pattern, AI assistant, Local-Grammar Graph,
Chinese-Korean translation, DECO tagset

\section{Introduction}

This research focuses in describing and formalizing diverse request patterns in Chinese for the automatic classification of music-request sentences in AI assistant platforms. In this study, when various sentence types in Chinese are classified into appropriate discourse categories, they are also annotated with request type tags and Korean counterparts, which would be crucial for switching Chinese request sentences with Korean ones and vice versa.

Based on the current development of artificial intelligence technology, a large number of AI speakers come into the Chinese market. However, most of them appear with the motivation of grabbing the entrance of the hardware market or just of merging with the product ecology. For instance, the manufacturing orientation of Alibaba AliGenie is used for convenient shopping experiences and household appliance controls. As a matter of fact, the diverse motivations of manufacturing AI speakers are not satisfying because most of them lack high-end human language understanding. As well known, in the area of 'making machine understand what a person is saying' (semantic recognition), speech interaction technology is mainly divided into Automatic Speech Recognition (ASR) and Natural Language Processing (NLP), where the latter still requires a huge improvement of linguistic resources to be performed properly. Linguistic resources such as electronic lexicons or large-scale corpora are crucial for a machine learning methodology as well as for a lexicon-based approach. Moreover, well-designed hybrid methods may be conducted on the basis of machine learning and statistical algorithms but can also use electronic lexicons and local patterns.

Figure 1 is the screenshot of the instruction manual for "Tingting 9420 Speakers" designed by Tencent. It is possible to observe some example sentences in the "Music" functional area (e.g. "Play music", "play my playlist", "save the playlist", "put some 
light music").

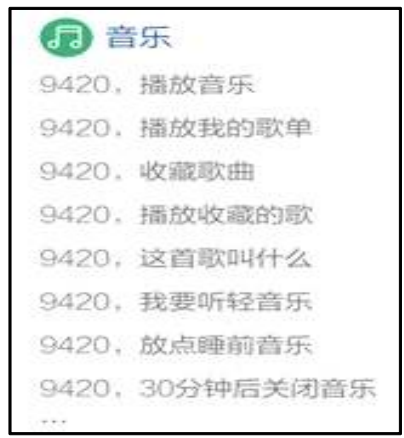

$<$ Figure 1> The screenshat of instuation manual for "Tinging Speakess"

These example sentences belong to different functional categories in music-listening domain. Besides, it is also noticeable that the same request can be expressed in different patterns in this field. When users want to play a song, a genre of music, or want to listen to something, they might say "I want to listen...", "Put me a song...", or "How about some music...?".

However, if a request statement cannot be correctly identified, then the whole experience will be suspended. Furthermore, due to the domain characteristics of music listening, the sentences spoken to operate the corresponding functions show limited syntactic and semantic features. This indicates that it is necessary to properly classify the function categories in this field.

\section{Related works}

Traditional intention recognition methods mainly include rule-based semantic recognition methods and the method based on statistical feature classification algorithm. The general method is to extract information including musician, music library, style, character relationship, etc. from a large number of corpus texts and classify them into the dictionary. For example, Prager et al. (1999) used a rule-based 
method to construct rules and category information to classify user request text.

Ramanand, J., Krishna Bhavsar, and Niranjan Pedanekar (2010) proposed a rule-based method for consumer intention recognition to obtain user intentions and achieved good classification results. The research by Li, Xin and Dan Roth (2015) confirmed that different expressions will lead to an increase in the number of rule templates in a specific domain, which requires a lot of manpower and material resources. Therefore, although the method based on rule template matching does not require a large amount of training data, it can ensure the accuracy of recognition.

However, the shortcomings are also obvious. Since the user's sentence patterns are ever-changing, and the rules can only cover a relatively small part. The more written rules are also extremely difficult to maintain, and conflicting rules may often occur.

The method based on statistical feature classification requires the extraction of key features of the corpus text, such as characters, word features, N-Gram, etc., and then trains the classifier to achieve intent classification. Chen (2014) SVM and Naive Bayes classifier were used to classify Weibo corpus for consumption intention, and the F1 value reached more than $70 \%$. However, both of these two classifiers require manual extraction of features, which is not only costly, but also the accuracy of features cannot be guaranteed. It may also cause data sparseness.

Jia (2016) introduced AdaBoost algorithm and PSO algorithm to optimize SVM parameters using PSO. And he used the AdaBoost algorithm to integrate the PSOSVM classifier to obtain a strong AdaBoost-PSOSVM classifier. The experimental results show that the classification performance on the same data set is significantly higher than that of the SVM classifier. However, none of these methods can accurately understand the deep semantic information of user text.

With the development of deep learning, more and more scholars have used word vectors, Convolutional Neural Networks (CNN), Recurrent Neural Network (RNN) and Long Short-Term Memory (LSTM) network, Gated Recurrent Unit (GRU), attention mechanism and capsule network are used in intention recognition tasks. Compared with traditional machine learning methods, deep learning models have greatly improved recognition performance. 
However, there are still many difficulties in the current intention recognition work. For example, the irregularity of the text, the diversity of user intentions, etc. In addition, the biggest difficulty lies in the acquisition of annotation data. For example, Su et al. (2019) spent 4 months to build a complete annotation data set in order for the model to learn the ability of automatic completion. At present, the acquisition of annotation data mainly comes from two aspects. On the one hand, a dedicated data annotation team labels the data, and on the other hand, the annotation data is automatically generated in a semi-supervised manner.

Hwang et al. (2020) also proposed a pattern-based approach in classifying Korean AI assistant dialogues. In this way, the authors constructed local-grammar graphs to recognize corresponding sentence types. The f-measure result of this study achieved more than 70\%. Compared with the traditional rule-based method, such a pattern-based method can save a lot of repetitive work through the DECO electronic dictionary (Nam 2018) and the subgraphs in the UNITEX platform (Paumier 2003).

This research suggests a lexicon and pattern-based approach as in Hwang et al. (2020). Since current machine learning methods and statistical algorithms are not satisfying in recognizing and classifying diverse sentence types in AI assistance platforms, unless a huge size of annotated corpus is provided. The method proposed in this paper can annotate the corpus by adding tags to the Finite State Transducer (FST) on the Unitex platform, and generate annotated corpus. The experimental results also prove that the LGG grammar we constructed on the basis of DECO Korean Electronic dictionaries has good coverage of request corpus patterns in the music field. In addition, compared with the research by Hwang et al. (2020), request patterns are translated into a Korean counterpart after the construction of Chinese, which enables large-scale bilingual annotated corpus with diverse tags in the field of music listening. By comparing with the results of Google Translate, this language resource reflects a more authentic Korean counterpart in the field of music listening. 


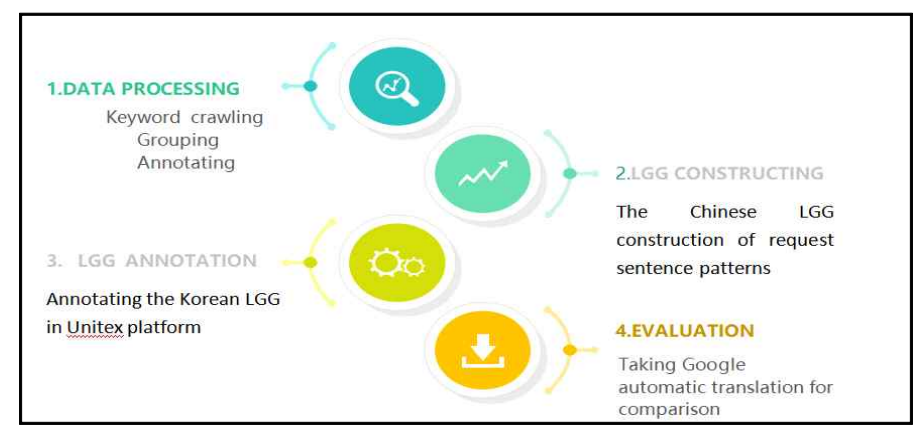

$<$ Figure 2> Overview of the study

\section{Grammatical features of Mandarin Chinese}

According to the data collected, the most frequently used sentential patterns are imperative, BA construction, declarative, and interrogative. It is necessary to briefly examine grammatical features of different sentential patterns so it is possible to acquire beneficial distinctions when attempting to construct the local-grammar graphs subsequently.

\subsection{Imperative sentences}

Imperative sentences are phrases that expresses a command, requests urging, advice, warning or consultation. Most are accompanied by an imperative intonation or a tone, generally, the subject position of an imperative sentence is often omitted (Zhu 1982: 205). A large amount of collected corpus data also proved this affirmation, as shown in (1a).

(1) a. 放 点 音樂

fang dĩan yīnyue

release some music

Play some music! 
The predicate of an imperative sentence is always a verb. Also, the honorific verb '請 (please)' is often used at the beginning of an imperative sentence for euphemism as in (2a). In written language, an exclamation mark is often added at the end of the request to express the command.

(2) a. 請進 !

Q̌ing jìng

HON3) come in

Come in, please!

Lastly, according to "Grammar Lectures" (Zhu 1982: 207), modal particle words are widely used, especially in the imperative sentences with prohibiting and warning implications. For this reason, Zhu discovered that modal particle words "了" applied with verbs appear $86 \%$ of the time, among all modal particle words. The modal particle terms '䧹', '吧', '唄, '好了' and their variations are frequently used in imperative sentences. Furthermore, in written Chinese, punctuation marks of imperative sentences '!' and '。' are used for marking strong emotional expressions. (Zhu 1982: 209)

\subsection{BA constructions}

As a special form of sentence structure in modern Chinese, BA construction emphasizes the result or mode of behavior. It is worth remembering that the basic order of mandarin Chinese is SVO as shown in (3a). However, in BA construction, the basic order is changed into ' $\mathrm{S}+\mathrm{BA}+\mathrm{O}+\mathrm{Vt}$ ' as in (3b).

\section{(3) a. 我 打開 了4) 音樂}

3) The Abbreviation of Honorific (The same as below).

4) There are two syntactic meanings of the Chinese characters "了". Here is the first applicability is a perfect aspect, hereinafter referred to as ASP (The same below). (Chinese Academy of Social Sciences 2012: 784) 
wǒ dăkāi le yīnyùe

1S open ASP music

I turned on the music.

b. 我把音樂打開了5)

wǒ bă yīnyùe dăkāi le

1S PREP music turn-on PART

I turned on the music.

Besides, the predicate of the BA construction should be a transitive verb in almost all cases.

\subsection{Declarative sentences}

The declarative sentence refers to the sentence pattern that states a fact or the speaker's opinion. The command tone of declarative sentences is mainly realized through verbs that express the speaker's wishes as in (4a). For example, the verbs like ‘想 (want)', ‘想要 (wish)', etc.

(4) a. 我想打開窗戶

wǒ xiăng dăkāi chuānghu

1S want open window

I want to open the window.

\subsection{Interrogative sentences}

Generally, Chinese interrogative sentences are divided into 4 types: general questions, the positive and negative questions, questions with interrogative pronouns, and alternative questions. It is worth noting that Chinese interrogative sentences also follow the word order of SVO. In this case, Q-Words (Question Words) appear in the object position.

5) Here is the second usage of the Chinese characters "?", a particle (Abbreviated as PART, the same below), which means a new situation. (Chinese Academy of Social Sciences 2012: 784) 
（5） a. 可以帮我拿一下那本書嗎?

kěy̌̌ bāng wǒ na yixia na běn shū mā ?

Aux help 1S take ADV DET CLA book QUES

Can you pass me the book?

The general question is the most frequently used interrogative pattern. As shown in (5a), the morphological features of question maker “嗎” usually added at the end of a declarative sentence as shown in (5a). For euphemism, auxiliary verbs that express possibility are usually inserted at the beginning. In addition, the insertion of verbs that expresses the meaning of the request at the beginning of the sentence can make the request more euphemistic.

\section{Classification of Chinese request patterns in AI-assistant platforms}

\subsection{Main categories}

Local grammars are a powerful tool to represent the majority of linguistic phenomena. Users may use finite-state grammars and diverse devices provided in the Unitex platform to directly edit linguistic patterns through LGGs to match language phenomena.

As mentioned above, this study is based on the function categories proposed by Hwang et al. (2020) for Korean request sentences in AI-assistant platforms. By analyzing the corpus built from social media texts and the results of the questionnaire, Chinese request sentences were divided into four categories, and further expanded to its subcategory. This paper adds the category of music search function [Search-Sub]. When receiving a user's request such as "Play some Starbucks music", the priority is to search in the local cache, such as [Music-On-Off]. If not, the request will be directly transferred to [Search-Sub]. 


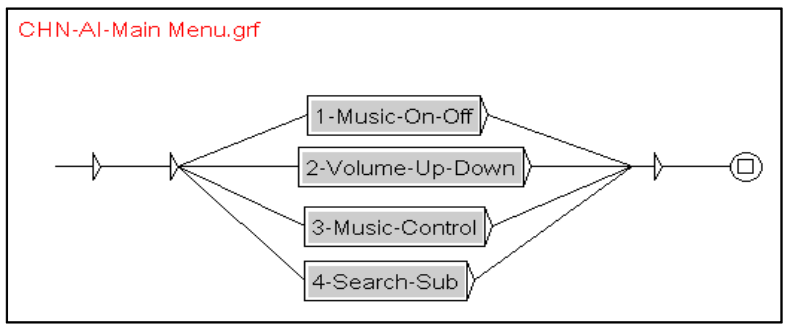

$<$ Figure 3> The main function categories

In order to classify these sentence types in a concrete way, the named entities that serve as topic words or focus of discourse should be properly described and recognized. The entity nouns under a sub-graph form as shown in Figure 4 and 5 and also divided into specific and random parts respectively. The graphs surrounded by the red Input variable in Figure 4 are sub-graphs that containing the name of the singer and the song (i.e. \{Entities-Singer\}, \{Tracks-Song\}). By adding Input and Output variables at the end of the FST, important information about request patterns can be extracted or annotated. Among the named entities of this domain, artist names obtained by web crawling are temporarily saved as related lists in the sub-graph \{Entities-Singer\}. The sub-graph \{Tracks-Song\} is located on the right side of \{Entities-Singer\}. Along the path there is also a sub-graph that contains data about the song title in the form of a list, and processes song title information that appears in the input text. $\{$ Singer-Sub\} is another sub-graph that was built to recognize the song's modifier in \{Tracks-Song\} and patterns like "Released in March 2012" can be recognized here.

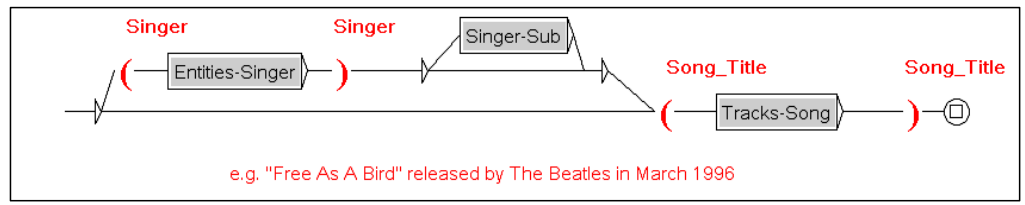

$<$ Figure 4> Subgraph of named entities (song list) 
$<$ Table 1> The combination structure of Named Entity

\begin{tabular}{|c|c|c|c|}
\hline & Structure & Play Mode & illustrative sentence \\
\hline a. & $\{$ Singer $\}$ - Song $\}$ & SPECIFIC & Play the Beatles' Hey Jude \\
\hline b. & $\{$ Singer\}-music & RANDOM & Play the Beatles' music \\
\hline c. & $\{$ Song\} & SPECIFIC & Play the Hey Jude \\
\hline d. & $\{$ Genre\}-music & RANDOM & Play rock music \\
\hline e. & $\{$ Propensity $\}$ & RANDOM & $\begin{array}{c}\text { Play some music which is suitable } \\
\text { for studying }\end{array}$ \\
\hline
\end{tabular}

The named entities \{singer/song/genre/propensity\} can occur in complex combinations, as illustrated in table 1 . The request can be either a specific song or a random song of an artist (or a certain genre). It is worth noting that when the song that the user wants to play does not exist in the local music, it will directly switch to the search function (i.e. [Search-Sub]). In the search function, richer patterns were defined to support custom search. The presentation of named entities (randomness) is displayed in figure 5. More details are discussed in Section 4.2.

\subsection{Request category of MUSIC-ON-OFF}

In order to distinguish the request category and the LGG category, square brackets were used to mark the request (i.e. [ ]), and the curly brackets used to mark the LGG component (i.e. \{ \}). A further observation was carried out over internal INPUT and OUT-PUT functions (i.e. random\$ XXX \$random, playlist\$ XXX \$playlist) to indicate the action of randomness or that of intentionality. In Figure 5, 5 combinations (randomness) based on singer, song, genre, propensity, playlist are described. The parts matching \{SongTracks\} and \{Playlist\} in patterns are output as annotation (i.e. 'RandomList' or 'Playlist') through the blue Output variable. 


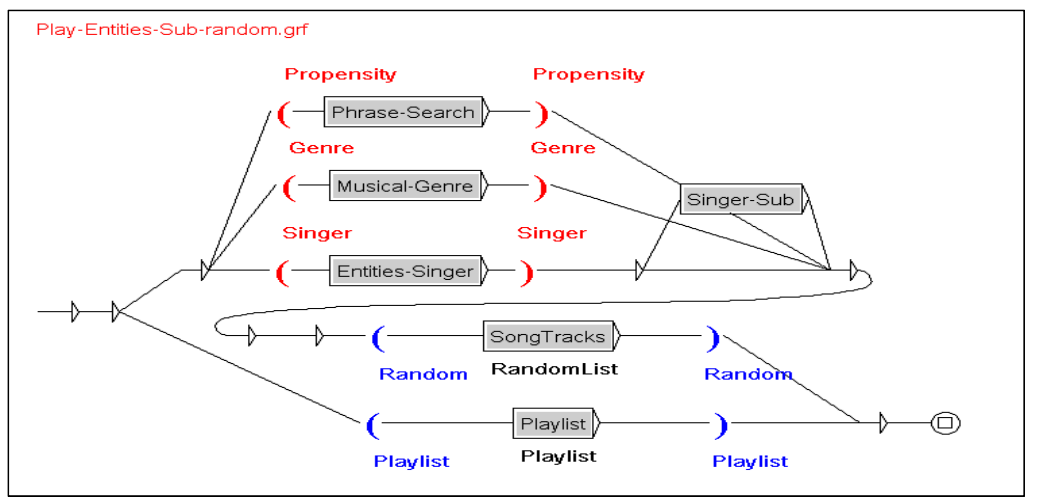

$<$ Figure 5> Subgraph of named entities (randomness)

As a semantic contradiction, the specific title of a song cannot be modified by quantifiers like “一些 (some)". This also goes for the predicate such as "來 (come)" or "放 (put)" means "play" in spoken Chinese which usually followed by a noun phrase. On the contrary, verbs like '播放 (play)' seem to be more natural when appear before a specific song title. On this account, predicate of [MUSIC-ON-OFF] category was divided into two parts; predicate followed by the specific title of song \{Verb2a\} (i.e. \{Predica-play2a-Quentifier\}) and predicate that can only semantically followed by random songs $\{$ Verb2b\} (i.e. \{Predica-play2b-Quentifier\}). The sub-categories of [music-on] and [music-off] primarily differ in the object section. Due to the economic principle, speakers prefer to express the request of "shut down" by "general" form instead of "specific" form. For instance, people may prefer the pattern of "shut down the music" than "shut down the song sung by \{singer\}".

This part aims to summarize the composition of the request as much as possible by using named entities and predicates. Figure 6 shows the LGG of Turn-On-Sub. The gray shaded structure is the component containing the sub-graph. \{Pronoun\} represents the set of personal pronouns and $\{$ Modal $\}$ is the set of modal particles in Chinese. According to "Grammar Lectures" (Zhu 1982: 208), "modal particles are function words that express mood and they are often used to express various moods at the end of a sentence or at a pause in a sentence". Here, common modal particles 
are '的, '了', '么', '呢, '吧, and '啊'. \{Qus_Marker\} represents the question marker set. Request patterns are divided into imperative sentences, declarative sentences, interrogative sentences and BA construction according to different sentence patterns. Since the LGG of $\{$ Turn-On-Sub\} and $\{$ Turn-OFF-Sub\} only differ in predicate part, it won't be repeated it here.

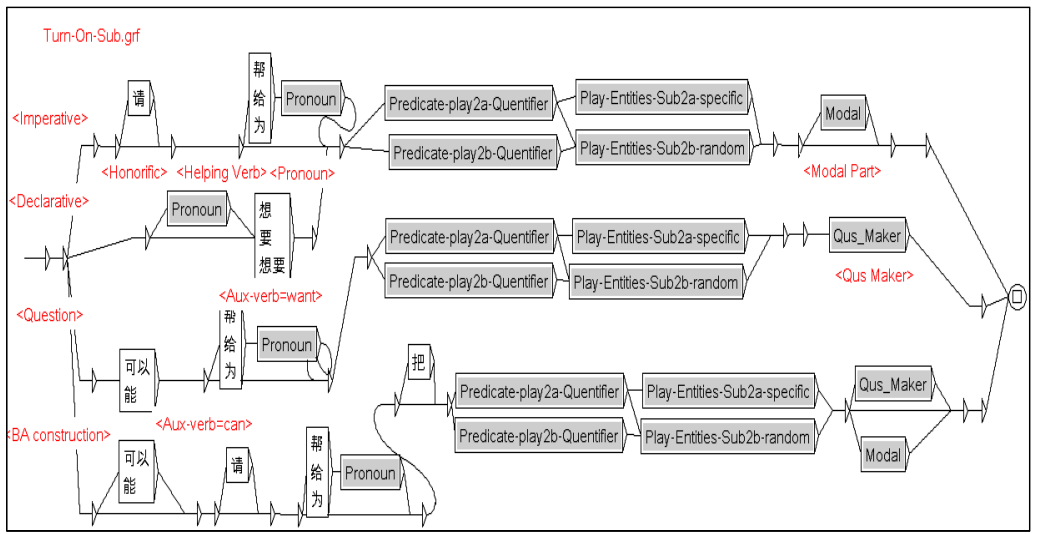

$<$ Figure 6> Local grammar graph of Tum-On-Sub category

Besides, the end of the FST is marked by function and this can be helpful to generate annotated corpora with XML format annotation. For example, the annotation outcome of the request pattern "Play some Beatles' music." can be represented as " $<$ Action $>$ Play some Beatles' music. $</$ Singer= Beatles, Song=Random, Act=Music-On>."

\subsection{Request category of VOLUME-UP-DOWN}

Concerning the request sentences about volume adjustment command, 5 levels were classified according to the user-adjusted intensity. First, if there are no adverbs of degree modifying the verbs in the patterns, they were set as default intensity. The second level is the degree of low intensity, semantically described by adverbs like “一点”. In this case, it modifies the predicates or adjective like “一些” also affecting 
the object "volume". Whether an adverb directly changes a verb or an adjective modifies a patient, 'volume' implies a low-intensity adjustment.

Also, it has to be considered that the highest intensity is uniquely expressed by hiring the adverb of degree "最" which means "most" in mandarin Chinese. In general, the adverb of degree "最" is followed by an adjective like "大/高” (big/high) and “小低" (small/low), referring to the adjustment upward or downward. We set the 4th level as the patterns consist of numeral, the most accurate expression among the 5 levels. Also, the last intensity was adjusted to a volume adjustment function to 0 intensity. In this lot of idioms in spoken language were added - for example, “靜音 (mute)”, “別吵 (don't make any sound)”.

The composition of the predicative phrases for [Volume-Up-Down] category can be represented as the graph in Figure 7. By adding an XML tag to the degree adverb “最(most)” (ie \$|Intension3(最/MAX)\$|Intension3) and calling the function at the end of the FST, it was possible to obtain the annotated request “音量調到最 $<$ Act=Volume-up $>$ 大 $</$ Intension=MAX $>$."

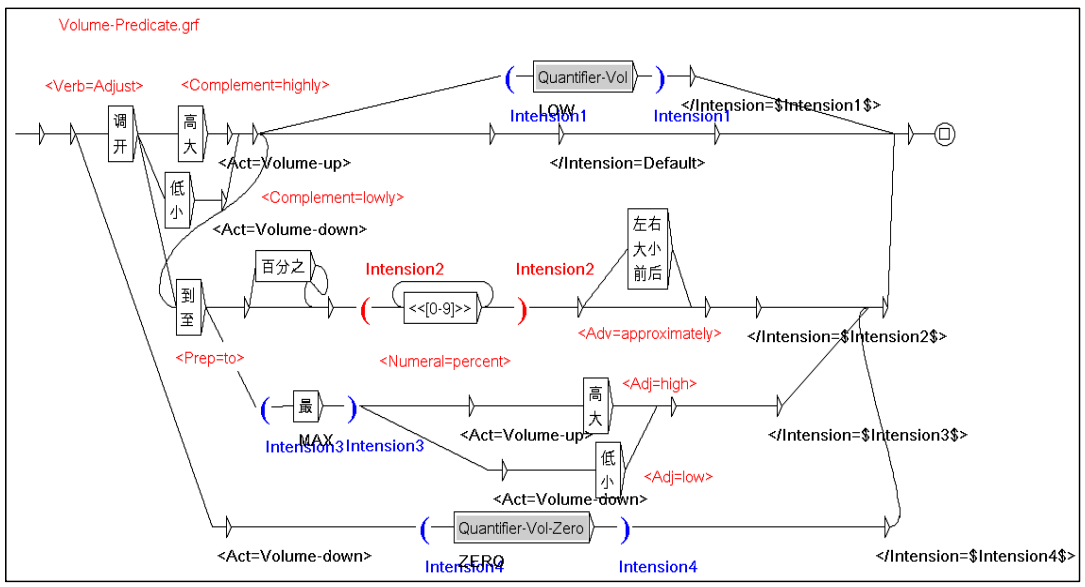

$<$ Figure $7>$ Subgraph of $\{$ Volume-Predicate $\}$

As the [Music-On-Off] category, the imperative sentences, declarative sentences, interrogative sentences and BA construction were divided according to different sentence types. 
This section is illustrated by the annotation result in table 2 .

$<$ Table 2> Intensity classification of [VOLUME-UP-DOWN] category

\begin{tabular}{|c|c|c|c|c|}
\hline LEV & Request sentence & Keyword & Intensity & After Annotation \\
\hline 1 & $\begin{array}{c}\text { 調高音量 } \\
\text { Turn up the volume. }\end{array}$ & $\begin{array}{c}\varnothing \\
\text { (empty) }\end{array}$ & Defeat & $\begin{array}{c}\text { 調高 }<\text { Act=Volume-up }></ \text { Intension= } \\
\text { Default }>\text { 音量 }\end{array}$ \\
\hline 2 & $\begin{array}{l}\text { 能把音量調高一点嗎 } \\
\text { Can you turn up the } \\
\text { volume a bit? }\end{array}$ & 一点 & LOW & $\begin{array}{c}\text { 能把音量調高 }<\text { Act=Volume-up> } \\
\text { 一点 }>\text { Intension=LOW>嗎 }\end{array}$ \\
\hline 3 & $\begin{array}{c}\text { 把音量調到最低 } \\
\text { Turn down the volume to } \\
\text { the lowest. }\end{array}$ & $\begin{array}{c}\text { 最 } \\
\text { (most) }\end{array}$ & MAX & $\begin{array}{c}\text { 把音量調到最<Act=Volume-dow } \\
n>\text { 低 }</ \text { Intension=MAX> }\end{array}$ \\
\hline 4 & $\begin{array}{l}\text { 把音量調到百分之 } 80 \\
\text { Turn the volume to } 80 \% \text {. }\end{array}$ & $\begin{array}{c}<0-100>> \\
\text { (numeral) }\end{array}$ & $\begin{array}{c}\text { SPECIFIT } \\
\mathrm{Y}\end{array}$ & $\begin{array}{c}\text { 把音量調到百分之 } 80</ \text { Intension } \\
=80>\end{array}$ \\
\hline 5 & $\begin{array}{l}\text { 靜音 } \\
\text { Mute. }\end{array}$ & $\begin{array}{l}\text { 靜音 } \\
\text { idiom }\end{array}$ & ZERO & $\begin{array}{c}<\text { Act }=\text { Volume-down }>\text { 靜音 }<\text { Intensio } \\
\text { n=ZERO> }\end{array}$ \\
\hline
\end{tabular}

\subsection{Request category of MUSIC-CONTROL}

Four subcategories were set as possibilities to modify the action 'play' itself under the third request category [MUSIC-CONTROL]. The functions associated with this category have more subgroups than other functions in the music-listening domain. This is because many subcategories can be included into the corresponding upper category such as 'play the previous/ next/ current song', 'play it over and over', 'play it randomly' and 'stop/pause playing'.

\subsubsection{Music Control: Selective play}

As observed from the subcategories of [Music-Control], the operation of 'Selective Play' is to play the previous/ current/ next song or a list of tracks that were previously played on the playlist. According to the corpus, it could be seen that the verbs that occurred in these subcategories are more diverse than [Music-On/off] and [Volume-Up/Down] categories. It seems to show some correlation with the timeline. For instance, taking the predicates “返回/返到/回到 播放/ 打開/ 放 調到 調回/ 跳到 跳回......' almost all of them share a form 'root + postposition'. A high 
frequency of neologism ‘切歌” was also observed in crawled SNS data.

$<$ Table 3> The structure of verb phrase in [Selective Play]

\begin{tabular}{|c|c|c|}
\hline & structure & illustrative sentence \\
\hline a & [adv再次][v1播放][np上一曲] & Play the last song again \\
\hline b & [adv重新][v1播放][np上一首歌 $]$ & Play the last song again \\
\hline c & [v1返回][np上面一首歌] & Go back to the last song \\
\hline d & [v1跳回][adv剛剛][np邢首歌] & Skip to the last song \\
\hline e & [v11調到][np下一曲] & Skip to the next song \\
\hline f & [vp切歌] & Play the next song \\
\hline
\end{tabular}

By comparing the noun phrases in table 3, the modifiers of the head nouns show a high correlation with temporal and position concepts. The front modifier '上面' is a noun for the position in “上面一首歌 (the last song)". The modifier '剛剛' is an adverb of time appears before the noun phrase “剛剛那首歌 (the last song)".

Based on these discoveries, the verbs and noun phrases of these subcategories were expanded. The noun phrases are closely described in Figure 8. The parts matching key words in patterns will be output as annotation (i.e. 'Previous', 'Next' or 'Now') through the blue Output variable (i.e. $</$ Song $=\$$ Order\$, Act=Music-On>). For example, the concordance result of the request pattern “換到下一首歌 Change to the next song' after LGGs processing is $</$ Song=Next, Act=Music-On $>$.

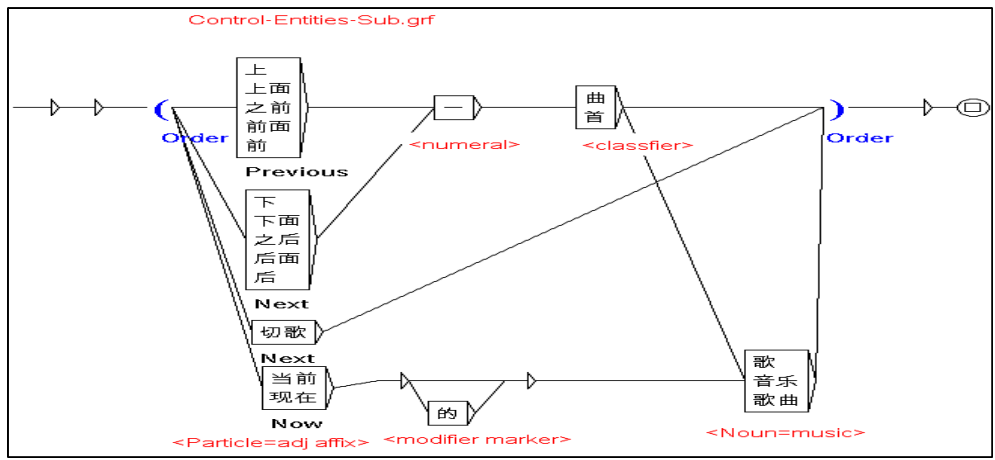

$<$ Figure 8> Composition of noun phrases in sub-graph 


\subsubsection{Music Control: Repeated play}

The [Repeated Play] category presents the cases where users want to repeat songs or specific music with a specific mood, including the previously mentioned 'previous/ current/ next' songs. Therefore, the category of [Selective play] including the named entity part discussed in [Music-On/Off] is worth referring to. The object of the loop playback can be a specific song name, a random song in a certain genre, or a previously played song. Since most of the requests that appear in the category of Music Control are only distinguished between the predicate and the object, the LGG representation won't be applied again here.

\subsubsection{Music Control: Random play}

This category represents a constituent that contains at least one individual. The realization of random request is mainly realized through adverbs that represents 'random'. Here, the predicate seems to be high repeat exposure due to a similar semantic meaning. The example collected from the database shows that the morphological feature of the adverb affix '地' is an optional factor here. Observations proved that the objects of [randomly play] category agree with the prediction. It is noteworthy that any noun phrases ended with '音樂歌 (music)' (RANDOM) can occur in this category as shown in (6a-d). That is, any request patterns that express random playback may contain one of the following four forms. The content enclosed by curly brackets is the singer, playlist, genre, and propensity information. The meaning of "random" is expressed by the following generic entity "Music".

(6) a. \{singer $\}$-music RANDOM

b. \{playlist\}-music RANDOM

c. $\{$ genre\}-music RANDOM

d. \{propensity\}-music RANDOM 
Finally, the [pause play] category consists of the sentences that express that you need to temporarily stop playing. In terms of the function itself, the request of stop playing can only be expressed by single vocabulary containing the meaning 'to stop' and seems to be similar to [Music Off] category.

Considering the economic principle already mentioned in [Music Off] category, speakers prefer to express the request of [pause play] function by 'pause music' instead of 'pause the music of [singer]'. Through the collected corpus, it was observed that the request of this functional category is realized mainly through BA construction and imperative sentences. In spoken Chinese, to achieve the purpose of emphasizing the request is necessary to advance the object in BA construction. For example, ‘把晋樂暫停一下' can be transcribed as 'make the music stop', emphasizing the patient by moving object to the front of sentences. Besides, the verb '播放 (play)' whose part of speech is verb in other categories. However, '播放 (play)' is the object of verbs that express the meaning of "pause" as in Figure 9.

\subsection{Request category of SEARCH-CONTROL}

In addition to the constructed named entities (i.e. Figure 4 and Figure 5), the user-defined search may also search for music genres and propensity. The sub-graph \{Musical-Genre\} presents genres of music. Sub-graph \{Phrase-Search\} indicates the patterns used when the user customizes the search. By using the Input variable.

Since the request patterns consist of the form of noun phrases, it is possible to apply the machine-readable dictionary in propensityo) part, This means that adjectives like 'pleasant' in the phrase 'pleasant music' can be concentrated by attaching internal tags of the same category. However, because of the lack of Chinese machine-readable dictionary, it is foreseeable that the recognition and classification performance of this part might be unsatisfactory.

6) Propensity: phrase search meaning request patterns like "The songs suitable for studying". 


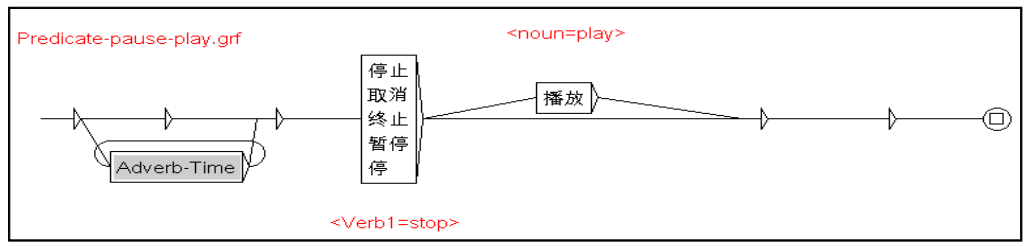

$<$ Figure 9> Subgraph of verb constituents

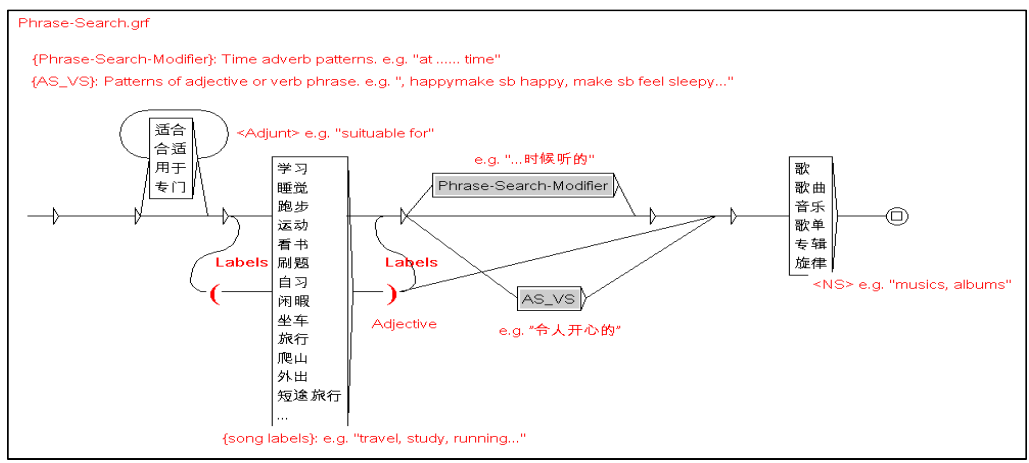

$<$ Figure 10> Subgraph of $\{$ Phrase-Search $\}$

Figure 11 shows the result of annotation based on FST in the Unitex platform.
$\{\mathrm{S}\} \leq \mathrm{Act}=$ Volume-down $>$ 静音 $</$ Intension=ZERO $>$. $\{\mathrm{S}\}$
$\{$ S $\} \leq$ Action>下载适合学习时候听的歌 $</$ Singer=, User Search=适合学习时候听的歌. Song Labels=学习.Act=Search>
$\{$ S $\} \leq$ Action>打开周杰伦的歌 </Singer=周杰伦.Song Random=random, Song Title=Act=Music-On>
$\{\mathrm{S}\} \leq$ Action>打开周杰伦的歌 $</$ Singer=周杰伦.User Search=random, Song Labels=.Act=Search>
$\{$ S $\} \leq$ Action>播放与火星的孩子对话 $</$ Singer=, Song Random=, Song Title=与火星的孩子对话Act=Music-On $>$
$\{\mathrm{S}\} \leq$ Action>播放与火星的孩子对话 $</$ Singer=, User Search=,Song Labels=,Act=Search $>$
$\{S\} \leq$ Action>播放学习歌单 $</$ Singer=, User Search=学习歌单, Song Labels=学习.Act=Search $>$
$\{$ S $\} \leq$ Action>播放电子音乐</Singer=,User Search=电子音乐.Song Labels=,Act=Search>
$\{S\}$ 帮我把音量调到最 $<A c t=V$ olume-up $>$ 大 $</$ Intension=MAX $>\{S\}$
$\{S\}$ 能帮我把音量调高 $<A c t=V$ olume-up $></$ Intension=Default $>$ 吗. $\{S\}$
$\{S\}$ 请把音量调到最 $<A c t=V$ olume-down $>$ 小 $</$ Intension $=M A X>\{S\}$
$\{S\}$ 章垔调到百分之 $80</$ Intension $=80>$. \{S\}
章量调高 $<A c t=V$ olume-up $>-$ 点 $</$ Intension $=L O W>$. $\{S\}$

$<$ Figure 11> Some concordance results in Unitex platform

\section{Korean annotation of Chinese request sentences}


The second goal of the classification and description of the request sentences in Chinese is to adopt these domain-dependent data in automatic translation such as Chinese-Korean request sentence translation. From this viewpoint, Chinese meaningful strings Korean counterparts were annotated on the basis of the DECO Korean Electronic dictionary. In this way, Chinese request sentences would be classified and annotated according to the DECO-Request-Tagset, and thus paired with corresponding Korean request sentences.

\subsection{Annotation rules}

Due to the complex morphological and grammatical features of Korean, this study was focused on the grammatical features of Korean inflectional endings when doing translation and deliberately ignoring some parts of the lexical correspondence. Only the major categories were considered and any further subdivision were ignored. For example, the existence of honorific systems in Korean and Chinese was taken into consideration but its subdivision was ignored. In this case, Chinese honorific markers were translated into ' -어요' in Korean.

Besides, imperative sentences in Chinese are less typical than Korean ones so the approach was conducted in a semantic level. For example, first, the Chinese honorific maker '請' as '-어요' in Korean was taken on account of both of them expressing respect for listeners. The Chinese character '帮' wa then transcribed into '주다' in Korean, both of them being used as auxiliary verbs and modifying main verbs from a grammatical viewpoint.

Third, since imperative sentences in Chinese are mainly composed of a main sentence and modal particle words such as '啊', '呀', and so on, we translate modal particles into '어라' in Korean. However, modal particle word '吧' softens the tone of command in imperative sentences. On this level, modal particle words such as '吧' are transcribed into '봐' that contains the meaning of 'trying to do something'.

Finally, due to the influence of the special construction of the BA construction on the verbs in Chinese, the verbs in BA construction were translated into causative 
expressions of the corresponding Korean verbal phrases such as ' 게 해'. According to "Grammar Lectures" (Zhu 1982: 185), BA construction shifts the patient ahead to emphasize the agent's control over the patient. The annotation rules are described in table 4.

<Table 4> Rules of Korean annotation for Chinese request sentences

\begin{tabular}{|c|c|c|}
\hline & Features of Chinese annotated LGG & Translation of Korean LGG \\
\hline 1 & $\begin{array}{c}\text { Pronoun honorific and verb honorific } \\
\text { \$_静/磨煩/憨/...\$\$ }\end{array}$ & $\begin{array}{l}\text { Honorific markers } \\
\text { \$_\{어\}-요_\$' }\end{array}$ \\
\hline 2 & $\begin{array}{l}\text { Auxiliary verbs } \\
\text { \$_帮-ProN-Verb_\$ }\end{array}$ & $\begin{array}{c}\text { Auxiliary verbs } \\
\text { \$_\{어\}-<주다>_\$ }\end{array}$ \\
\hline 3 & $\begin{array}{l}\text { Modal particle words of imperative } \\
\$ \_ \text {啊/呀/唄/…\$ }\end{array}$ & Final ending \\
\hline 4 & $\begin{array}{c}\text { Modal particle words of Euphemism } \\
\text { \$_吧_\$ }\end{array}$ & $\begin{array}{l}\text { Euphemism/Auxiliary } \\
\text { \$_\{어\}-<보다>_\$ }\end{array}$ \\
\hline 5 & $\begin{array}{c}\text { BA construction } \\
\text { \$_把_\$ }\end{array}$ & $\begin{array}{l}\text { Causative expressions } \\
\text { \$_\{게\}-<하다>_\$ }\end{array}$ \\
\hline
\end{tabular}

5.2 Representation of annotation rules by finite-state graphs

To implement the system that recognizes and classifies request patterns in specific domain, language resources with refined description of language patterns were required. For this purpose, it is possible to formalize the results of the study and use them as language resources for recognizing and classifying request sentences in AI-assistant platforms. The UNIITEX platform is used because the finite-state graphs will be transformed automatically finite-state grammars that allow generating request sentences $(<$ Figure $12>)$. 


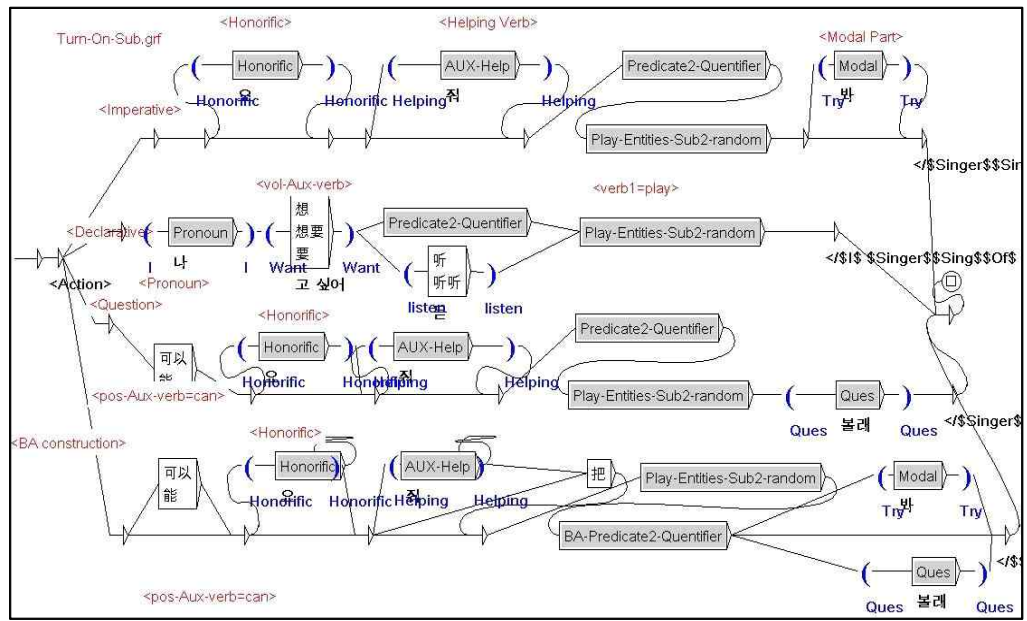

$<$ Figure 12> Korean annotation example of Chinese request sentences

\section{A twofold evaluation}

\subsection{Performance Evaluation of Chinese request sentence FST}

One of the great advantages of FST is directivity. Each path represents contextual information about the different functional categories. The tag annotated under the patterns represents the information required for the functional categories to be performed by calling input and output variables. The annotation is attached by inserting XML tags before and after the formalized grammar.

In order to evaluate the performance of the finite-state graphs that was built above, some users were recruited to directly obtain the corresponding patterns of request patterns in the music-listening domain, composed as test data. Attaching XML tags to the observed patterns helped to obtain the correct answer. By applying test data to rhe previous Chinese graphs in the Unitex platform, an annotated corpus with attached XML tags and 500 sentences was obtained. Finally, the accuracy of the model was checked by comparing whether the XML tag is attached correctly or not. Furthermore, 
f-measure method was applied to evaluate the performance of constructed Chinese graphs.

$<$ Table 5> Evaluation result

\begin{tabular}{|c|c|c|}
\hline & P(Predicated) & N(Predicated) \\
\hline P(Actual) & TP(True Positive): 428 & FN(False Negative): 36 \\
\hline N(Actual) & FP(False Positive): 62 & TN(True Negative): 24 \\
\hline
\end{tabular}

Table 5 shows the evaluation results of the Chinese sentence pattern graphs in the music-listening domain. The precision and recall rates are $87.35 \%$ and $92.1 \%$ respectively, and then f-measure ( $\mathrm{F} 1$ score) shows $89.6 \%$. It is possible to observe that simple imperative sentences show better automatic recognition and classification effects (e.g the sentence "Open Alice's Song!'), which indicates a sentence type of 'play randomly a certain singer's song'.

However, 'less request' patterns failed to be recognized from the original corpus. For example, a sentence "Too noisy!" that implies the turning down the volume was not properly classified. Also, due to the lack of a Chinese machine-readable dictionary, it is not possible to include all predicates of the same type, naturally affects the recognition outcomes.

\subsection{Performance Evaluation of Chinese-Korean translation}

In order to evaluate the performance of the finite-state graphs that include Chinese-Korean translations, a total of 550 sentences were extracted from social media texts. The process done in this stage was to manually compare the result of the application of the finite-state graphs of Chinese-Korean translations with the correct annotation and classification. The result shows that about 33 sentences were not recognized by the finite-state graphs. In addition, some sentences show obvious grammatical errors. Even though they do not affect the understanding of semantics, this is one of the inevitable shortcomings of the annotation model advocated in this study. The screenshot in Figure 13 shows a sample of the text with Chinese-Korean 
translation results.

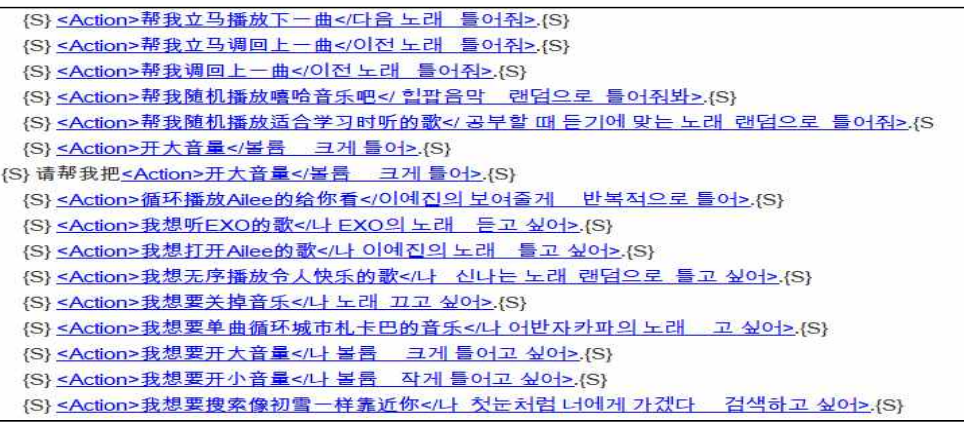

$<$ Figure 13> Sample text with Chinese-Korean translation results

To fully reflect the advantages and disadvantages of this approach, a comparative analysis between the result of the finite-state graph application and the Google translator's Chinese-Korean translations was made from five perspectives.

First, the number of perfectly translated sentences was considered, since it can indicate whether a sentence reflects accurately the request or not.

Second, the number of sentences in which the verbs are translated incorrectly were counted. As mentioned above, the verb "play" in Chinese '打開' should be translated into "open": Google translates it into '열다', a literal translation, so it is not appropriate in this domain.

Third, the number of sentences whose category is incorrect was also counted. For example, translating imperative sentences into declarative ones is not correct. Google translator translates the Chinese imperative sentence of "turn on the music" into the Korean declarative sentence "전자 음악을 연주합니다", which is an incorrect process of translation. Instead, through the Korean translation process here proposed, the meaning of the imperative sentence and the verbs occurring in current domain were properly considered and thus were translated into a correct Korean sentence such as "전자 음악 켜봐".

Fourth, the number of sentences containing grammatical errors was taken into 
consideration. Since Korean has more complicated endings and inflectional morphemes, incorrect Korean inflectional endings may occur in the Chinese-Korean transformation process.

Finally, the number of sentences that contain wrongly recognized named entities were analyzed. Table 6 illustrates some examples of the results of the finite-state graph translation and those of Google translation.

$<$ Table 6> Compared result of FST translation and Google translation

\begin{tabular}{|c|c|c|}
\hline Chinese sentence & FST translation & Google Translator \\
\hline 請打開音樂 & 음악 틀어 & 음악을 켜십시오. \\
\hline 請打開EXO的咆哮 & EXO의 으르렁 틀어 & EXO의 으르렁 거리십시오. \\
\hline 請打開Ailee的給你看 & 이예진의 보여줄게 틀어 & Ailee를여십시오. \\
\hline 請打開我的歌單 & 내 재생목록 틀어줘 & 내 재생 목록을 여십시오. \\
\hline 帮我聲音開大吧 & 볼륨 크게 틀어봐 & 나를 켜십시오. \\
\hline 帮我關閉音樂吧 & 음악 꺼 & 음악이 꺼져 있습니다. \\
\hline 上一曲單曲循环 & 이전 노래 반복재생 & $\begin{array}{c}\text { 끝없는 루프에서 이전 } \\
\text { 노래를 재생합니다. }\end{array}$ \\
\hline 音樂打開 & 음악 켜 & 열린 음악 \\
\hline 快点帮我打開 & 틀어줘 & 도와주세요 \\
\hline$\ldots$ & $\ldots$ & $\ldots$ \\
\hline
\end{tabular}

In the evaluation section, Pattern error refers to patterns that are grammatically translated correctly but semantically wrong. For example, Google Translate translates 'make my voice louder' into '나를 켜십시오.' This type of error appears a lot in the results of Google Translate. Some grammatical errors were found in the FST-based translation results, such as 'I want to repeat EXO's songs' which was translated into 'EXO의 노래를 반복재생고 싶어'. 
$<$ Table 7> Performance of FST translation and Google translation

\begin{tabular}{|c|c|c|c|}
\hline & Evaluation & FST translation & Google Translator \\
\hline \multirow{2}{*}{ Perfect sentence } & Percent & $86.9 \%$ & $48 \%$ \\
\cline { 2 - 4 } & Quantity & 478 & 264 \\
\hline \multirow{2}{*}{ Verbal errors } & Percent & $0 \%$ & $30.29 \%$ \\
\cline { 2 - 4 } & Quantity & 0 & 167 \\
\hline \multirow{2}{*}{ Pattern error } & Percent & $0.01 \%$ & $26.86 \%$ \\
\cline { 2 - 4 } & Quantity & 5 & 148 \\
\hline \multirow{2}{*}{ Grammatical errors } & Percent & $2.68 \%$ & 0 \\
\cline { 2 - 4 } & Quantity & 15 & 0 \\
\hline \multirow{2}{*}{ Entities error } & Percent & $0 \%$ & $93 \%$ \\
\cline { 2 - 4 } & Quantity & 0 & 40 \\
\hline
\end{tabular}

The performance results of our LGGs-based application and Google translation of Chinese-Korean are compared in the table above. On the whole, the annotations in LGGs outperformed those of Google Translator in many aspects. First, the number of perfectly translated sentences (86.84\%) is significantly higher than Google's automatic translation (48\%). This outcome proves that, in cross-language situations, the corresponding annotation method can effectively solve the ambiguity problem. Moreover, since Google Translator does not limit the input sentences into a specific domain (e.g. music listening domain) this leads to verb usage errors caused by literal translation, a phenomenon that is not observed in the annotations in LGGs.

Moreover, due to the lack of obvious imperative sentence features in Chinese, machine translation usually does not include a corresponding translation mechanism for a sentence type, which also leads to ambiguity in requesting sentences. The last significant difference between the two approaches comes with the error of the named entities. In case of Google translation, $93 \%$ of entities are incorrect, whereas, since we manually described this correspondence, a quite high ratio of named entity correspondence was observed. This shows to some extent that in the process of building language resources, manual work is strongly required to improve the completion of language resources. 


\section{Conclusions}

This study verified the fact that the pattern-based model can accurately recognize and classify users' requests in the music-listening domain. Since there are no morphological markers in imperative sentences in Chinese, recognizing automatically request sentences coming from it and translating them into other languages (e.g. rich inflectional suffixes of Korean) is a quite challenging task in language processing. Through the methodology that was proposed in this study, a classification of Chinese request sentence types and a Korean counterparts was presented.

In this way, Chinese request sentences are classified and annotated according to the DECO-request tag set proposed for Korean, and thus well paired with corresponding Korean request sentences. Based on the three main categories of AI speaker functions proposed by Hwang et al. (2020), this paper added a user-defined search mode based on music tags and emotional words. Constructing patterns in the field of Chinese music listening through FST demonstrated reliable text annotation and function classification capabilities based on annotation tags. The method proposed in this paper can annotate the corpus by adding tags to the FST on the Unitex platform, and generate annotated corpus, which is fundamental for deep learning-based method. The experimental results also prove that the LGG grammar we constructed on the basis of DECO Korean Electronic dictionaries has a meaningful coverage of request patterns in the music field.

\section{References}

남지순·최성용·황창회(Jeesun, Nam, Sungyong Choi, Changhoe Hwang). 2019.

${ }^{\circledR} \mathrm{DECO}$ 한국어 전자사전 컴파일과 유니텍스 플랫폼 사용 매뉴얼 $(D E C O$ Korean Electronic Dictionary Compilation and Unitex Platform User Manua)』. 서울: 한국외국어대학교 DICORA 연구센터(Seoul: Hankuk University of Foreign Studies DICORA Research Center).

남지순(Nam, Jeesun). 2018. 『코퍼스 분석을 위한 한국어 전자사전 구축방법론( $A n$ introduction to a methodology of implementing Korean electronic 
dictionaries for corpus analysis)』. 서울: 역락(Seoul: Youkrack Publishing Company)

황창회·윤소은 - 남지순(Hwang, Changhoe, Soeun Yoon, and Jeesun Nam). 2020. 「 $\mathrm{AI}$ 어시스턴트의 요청문 인식 및 분류 주석을 위한 음악청취 관련 문형 패턴 연구(A Study on Music-request Sentence Patterns in AI-assistant Platforms for the Automatic Classification and Annotation of Requests)」. "한 국언어과학회(The Korean Association of Language Sciences)』27.1:95-132. 胡壯麟・朱永生・張德祿・李戰子(Hu, Zhuanglin, Yongsheng Zhang, Delu Zhang, and Zhanzi Li). 2008. 『系統功能語言學概論 $(A n$ Introduction to Systemic-Functional Linguistics)」. 北京: 北京大學出版社(Beijing: Peking University Press).

朱德熙(Zhu, Dexi). 1982. 『語法講義(Grammar Lectures)』. 北京: 商務印書館(Beijing: Commercial Press).

中國社會科學院語言研究所詞典編輯室(Dictionary Editing Office, Institute of Language Studies, Chinese Academy of Social Sciences). 2012. 『現代漢語 詞典(Modern Chinese Dictionary). 北京: 商務印書館(Beijing: Commercial Press).

陳建美(Chen，Jianmei). 2009. “中文情感詞龨本体的构建及其應用(The Construction and Application of Chinese Emotion Word Ontology).” 碩士學位論文(MA thesis), 大連理工大學(Dalian University of Technology).

梅家駒・竺一鳴・高蓝琦(Mei, Jiaju, Yiming Zhu, Yunqi Gao). 1983. 『同義詞詞林 (Synonym Cilin)」. 上海: 上海辭書出版社(Shanghai: Shanghai Lexicographical Publishing House)

陳浩辰(Chen， Haochen). 2014. “基于微博的消費意圖挖掘(Consumption Intention Mining Based on Microblog).” 碩士學位論文(MA thesis), 哈爾濱工業大學 (Harbin Institute of Technology).

賈俊華(Jia, Junhua). 2016. “一种基于AdaBoost和SVM的短文本分類模型(A short text classification model based on AdaBoost and SVM).” 碩士學位論文(MA thesis), 河北工業大學(Hebei University of Technology).

Ahmad, Ahmad Sukri, Mohammad Yusri Hassan, Md Pauzi Abdullah, Hasimah Abdul Rahma, Faridah N. Hussin, Hayati Abdullah, and Saidur Rahman. 2014. "A review on applications of ANN and SVM for building electrical energy 
consumption forecasting." Renewable \& Sustainable Energy Reviews 33.2:102-109.

Carroll, John. 2003. "Parsing." In The Oxford Handbook of Computational Linguistics, edited by Ruslan Mitkov, 233-48. Oxford: Oxford University Press

David, Clemenceau. 1997. "Finite-State Morphology: Inflections and Derivations in a Single Framework Using Dictionaries and Rules." In FiniteState Language Processing, Language, Speech, and Communication, edited by E. Roche, and Y. Schabes, 67-98. London: MIT Press.

Gross, Maurice. 1997. "The Construction of Local Grammars." In FiniteState Language Processing, Language, Speech, and Communication, edited by E. Roche, and Y. Schabes, 329-54. London: MIT Press.

Gross, Maurice. 1993. "Local grammars and their representation by finite automata." In Data, Description, Discourse: Papers on the English Language in honour of John $\mathrm{McH}$ sinclair, edited by M. Hoey, 26-38. London: Harper-Collins Press

Hoard E. James. 1998. "Language understanding and the emerging alignment of linguistics and natural language processing." In Using Computers in Linguistics: A Practical Guide, vol. 1, edited by J. Lawler, and H. Aristar Dry, 197-230. London: Routledge.

Kim, Yoon. 2014. "Convolutional neural networks for sentence classification." Proceedings of the 2014 Conference on Empirical Methods in Natural Language Processing (EMNLP) 1746-51.

Liu, Bing, and Lan Lane. 2016. "Attention-based recurrent neural network models for joint intent detection and slot filling." Interspeech 2016 685-89.

Liu, Bing, and Lan Lane. 2016. "Joint online spoken language understanding and language modeling with recurrent neural networks." Proceedings of the 17th Annual Meeting of the Special Interest Group on Discourse and Dialogue 22-30.

Lu, Bin, and Benjamin K. Tsou. 2010. "Combining a large sentiment lexicon and machine learning for subjectivity classification." 2010 International Conference on Machine Learning and Cybernetics 3311-16.

Li, Xin, and Dan Roth. 2005. "Learning question classifiers: the role of semantic 
information." Natural Language Engineering 12.3:229-249.

Mesnil, Grégoire, Yann Dauphin, Kaisheng Yao, Yoshua Bengio, Deng Li, Dilek Hakkani-Tur, Xiaodong He, Larry Heck, Gokhan Tur, Dong Yu, and Geoffrey Zweig. 2015. "Using Recurrent Neural Networks for Slot Filling in Spoken Language Understanding." IEEE/ACM Transactions on Audio, Speech, and Language Processing 23.3:530-539.

McCallum, Andrew, and Kamal Nigam. 1998. "A comparison of event models for naive bayes text classification." Association for the Advance of Artificial Intelligence 41-48.

Paumier, Sébastien. 2003. Users' Manual of UNITEX Paris: Université de Marne-la-Vallée.

Prager, John, Dragomir Radev, Eric Brown, and Anni Coden. 1999. "The use of predictive annotation for question answering in TREC8." Conference of the Eighth Text Retrieval 199-411.

Ramanand, J., Krishna Bhavsar, and Niranjan Pedanekar. 2010. "Wishful Thinking Finding suggestions and 'buy' wishes from product reviews." Proceedings of the NAACL HLT 2010 Workshop on Computational Approaches to Analysis and Generation of Emotion in Text 54-61.

Robert E. Schapire, and Yoram Singer. 2000. "a boosting-based system for text categorization." Machine Learning 39.2:135-168.

Su, Hui, Xiaoyu Shen, Rongzhi Zhang, Fei Sun, Pengwei Hu, Cheng Niu, and Jie Zhou 2019. "Improving Multi-turn Dialogue Modelling with Utterance ReWriter." Proceedings of the 57th Annual Meeting of the Association for Computational Linguistics 22-31.

Jiabin $\mathrm{Li}$

DICORA/ Department of Linguistics and Cognitive Science,

Hankuk University of Foreign Studies

107 Imum-ro Dongdaemun-gu

Seoul, South Korea

E-mail: lijiabin951103@gmail.com

Changhoe Hwang

DICORA/ Department of Linguistics and Cognitive Science,

Hankuk University of Foreign Studies 
107 Imum-ro Dongdaemun-gu

Seoul, South Korea

E-mail: hch8357@naver.com

Jeesun Nam

DICORA/ Department of Linguistics and Cognitive Science,

Hankuk University of Foreign Studies

107 Imum-ro Dongdaemun-gu

Seoul, South Korea

E-mail: jeesun.nam@gmail.com

\begin{tabular}{|l|l|}
\hline Received & Nov. 6,2020 \\
\hline Reviewed & \\
\hline Accepted & \\
\hline
\end{tabular}

